\title{
A Semiempirical Quantum Approach to the Formation of Carbon Dioxide Adsorbates on Pt(100) and Pt(111) Cluster Surfaces
}

\author{
C. F. Zinola, ${ }^{\dagger}$ C. Gomis-Bas, ${ }^{\ddagger}$ G. L. Estiú, ${ }^{\S, l l}$ E. A. Castro, ${ }^{\S}$ and A. J. Arvia ${ }^{*, \perp}$ \\ Laboratorio de Electroquímica Fundamental, Facultad de Ciencias, Malvín Norte, Montevideo, \\ Uruguay, Departamento de Química-Física, Universidad de La Laguna, Avda. de la Trinidad, \\ 38204 La Laguna, Spain, CEQUINOR, Universidad Nacional de La Plata, Casilla de Correo \\ 962, 1900 La Plata, Argentina, Departamento de Ciencia y Tecnología, Universidad Nacional \\ de Quilmes, Roque Saenz Peña 180, Bernal, Argentina, and INIFTA, Universidad Nacional de \\ La Plata, Sucursal 4, Casilla de Correo 16, 1900 La Plata, Argentina
}

Received April 20, 1998. In Final Form: April 20, 1998

\begin{abstract}
The geometries and binding energies of $\mathrm{CO}_{2}$ adsorbates on $\mathrm{Pt}(100)$ and $\mathrm{Pt}(111)$ cluster surfaces were calculated by means of an improved version of the extended Hückel molecular orbital method. The polarization of the surface by an applied electric potential and coadsorption of $\mathrm{H}$ atoms were included in the model. For simulated applied potentials in the range -1.0 to $1.0 \mathrm{~V}, \mathrm{CO}_{2}$ coordination geometries (side-on, formate) involving two adsorbate atoms bonded to the surface are favored, regardless the surface topology and the presence of coadsorbed $\mathrm{H}$ atoms. In agreement with experiment, larger binding energies are always calculated for the $\mathrm{Pt}(100)$ cluster surface.
\end{abstract}

\section{Introduction}

Reactions of $\mathrm{CO}_{2}$ yielding energy-enriched products, most of them carbon monoxide derivatives such as formaldehyde, formic acid, and carbon monoxide have been studied on several metal electrodes in both aqueous and nonaqueous media. ${ }^{1-4}$ The distribution of reaction products depends on the nature of the electrode, the composition of the solution, and other operational conditions. ${ }^{1,5-7}$

The adsorption of $\mathrm{CO}_{2}$ on metal electrocatalysts ${ }^{8}$ is favored when $\mathrm{H}$-adatoms are present on the electrode, as it appears that the formation of $\mathrm{CO}_{2}$-containing adsorbates, usually denoted as reduced $\mathrm{CO}_{2}$ adsorbates, requires the simultaneous interaction of $\mathrm{CO}_{2}$ and $\mathrm{H}$-adatoms. Some of these adsorbates can be detected by anodic stripping voltammetry.

The role of $\mathrm{H}$-adatoms in the formation of reduced $\mathrm{CO}_{2}$ adsorbates has been studied combining spectroelectrochemical and voltammetric techniques on faceted and polycrystalline $\mathrm{Pt}$ and $\mathrm{Rh}$ electrodes in aqueous sulfuric acid. ${ }^{3}$ For (100)- and (111)-faceted Pt electrodes in acid solutions, two main anodic stripping current peaks have been recorded, which have been related to a weakly and a strongly $\mathrm{CO}_{2}$ adsorbate. The electrooxidation current

\footnotetext{
${ }^{\dagger}$ Laboratorio de Electroquímica Fundamental, Malvín Norte.

₹ Departamento de Química-Física, Universidad de La Laguna.

$\$$ CEQUINOR, Universidad Nacional de La Plata.

" Departamento de Ciencia y Tecnología, Universidad Nacional de Quilmes.

${ }^{\perp}$ INIFTA, Universidad Nacional de La Plata.

(1) Chandrasekaran, K.; Bockris J. O'M. Surf. Sci. 1987, 185, 495.

(2) Slater, S.; Wagenknecht, J. H. J. Am. Chem. Soc. 1984, 106, 5367.

(3) Arévalo, M. C.; Gomis-Bas, C.; Hahn, F.; Beden, B.; Arévalo, A.; Arvia, A. J. Electrochim. Acta 1994, 39, 793.

(4) Jitaru, M.; Lowy, D. A.; Toma, M.; Toma, B. C.; Oniciu, L. J. Appl. Electrochem. 1997, 27, 875.

(5) Paik, W.; Anderson, T. N.; Eyring, H. Electrochim. Acta 1969, 14, 1217.

(6) Kapusta, S.; Hackerman, N. J. Electrochem. Soc. 1984, 131, 1511.

(7) Liever, C. M.; Lewis N. S. J. Am. Chem. Soc. 1985, 106, 5083.

(8) Kazarinov, V. E.; Andreev, V. N.; Shelepkov, A. V. Electrochim.
} Acta 1989, 34, 905. peak ratio for these adsorbates depends on the potential sweep rate and solution composition. ${ }^{9}$

The formation of reduced $\mathrm{CO}_{2}$ adsorbates on $\mathrm{Pt}$ from aqueous environments is a surface-structure sensitive reaction, as demonstrated using different types of electrodes. ${ }^{3,4,9}$ Thus, in contrast to $\mathrm{Pt}(111),{ }^{10,11}$ the activity of $\mathrm{Pt}(100)$ for this process is relatively high. This crystallographic-face-dependent $\mathrm{CO}_{2}$ adsorption on $\mathrm{Pt}$ can be related to the difference in the electronic characteristics of the electroadsorptive sites and their relative distribution.

The complete anodic stripping of reduced $\mathrm{CO}_{2}$ adsorbates from Pt has been mainly related to the electrooxidation of CO- and CHO-type adsorbates to $\mathrm{CO}_{2} \cdot{ }^{1,3,12}$ Photoelectron spectroscopy has provided interesting results for the formation of both reduced $\mathrm{CO}_{2}$ adsorbates and their decomposition products, such as formate species on $\mathrm{Fe}$ and $\mathrm{Ni}$. ${ }^{13,14}$

Moreover, EMIRS (electrochemical modulated infrared spectroscopy) ${ }^{15}$ data have shown the presence of either $\mathrm{H}^{\circ} \mathrm{CO}$ or $\mathrm{HCO}_{2}{ }^{-}$adsorbates, whereas from SNIFTIRS (subtractively normalized interfacial Fourier transform infrared spectroscopy) ${ }^{12}$ data, the formation of linear, bridge, and multibonded $\mathrm{CO}$ adsorbates on $\mathrm{Pt}$ in $\mathrm{CO}_{2-}$ saturated aqueous acid solution has been confirmed. Otherwise, in-situ infrared spectra of $\mathrm{CO}$ and $\mathrm{CO}_{2}$ adsorbates on Pt electrodes are different, ${ }^{16,17}$ as the $\mathrm{C}-\mathrm{O}$

(9) Marcos, M. L.; González Velasco, J.; Vara, J. M.; Giordano M. C. Arvia, A. J. J. Electrtoanal. Chem 1989, 270, 205; 1990, 287, 99.

(10) Nikolic, B. Z.; Huang, H.; Gervasio, D.; Lin, A.; Fierro, C.; Adzic, R. R.; Yeager, E. B. J. Electroanal. Chem. 1990, 295, 415.

(11) Hoshi, N.; Mizumura, T.; Hori, Y. Electrochim. Acta 1995, 40, 883.

(12) Chandrasekaran, K.; Wass, J. C.; Bockris, J. O’M. J. Electrochem. Soc. 1990, 137, 518 .

(13) Wedler, G.; Ganzmann, I.; Borgmann, D. Appl. Surf. Sci. 1993 68,335

(14) Wambach, J.; Illing, G.; Freund, G. Chem. Phys. Lett. 1991, 184, 239.

(15) Beden, B.; Bewick, A.; Razaq, M.; Weber, J. J. Electroanal. Chem. 1982, 139, 203.

(16) Westerhoff, B.; Holze, R. Ber. Bunsen-Ges. Phys. Chem. 1993 $97,418$. 
stretching frequency resulting from $\mathrm{CO}$ adsorbates corresponds to a stronger bond than that resulting from reduced $\mathrm{CO}_{2}$ adsorbates. ${ }^{18}$ Furthermore, it has been proposed that $\mathrm{CO}$ adsorbates formed from $\mathrm{CO}_{2}$ electroreduction products may result from the decomposition of a more reactive species such as formate. ${ }^{19}$ Therefore, structural conclusions derived from spectroscopic data and mechanistic conclusions derived from electrochemical data for $\mathrm{Pt}$ in acids are not fully coincident. This subject becomes, thence, a challenging one that deserves more detailed experimental studies in order to be fully understood.

The calculation of the stability of the most likely adsorbates that can be formed on different Pt surfaces appears as an adequate approach for providing relevant information that helps the understanding of the much more complex situation prevailing at the electrochemical interface. This work is focused, thence, on the possible geometries and binding energies of reduced $\mathrm{CO}_{2}$ adsorbates on $\mathrm{Pt}(111)$ and $\mathrm{Pt}(100)$ cluster surfaces at different simulated electric potentials, calculated from a modified version of the extended Hückel molecular orbital method. Because of the complications associated with the experimental system, mainly related to the definition of the electrochemical interface involving reduced $\mathrm{CO}_{2}$ adsorbates, a simplified model has been chosen. This model considers the initial adsorption of $\mathrm{CO}_{2}$ on the uncharged Pt surface and the changes of the adsorbate when a simulated electric potential is applied. The relative influences of the negative applied potential and $\mathrm{H}$ coadsorption on $\mathrm{CO}_{2}$ sticking to $\mathrm{Pt}$ are then compared. The model allows us to identify the different species that are likely involved in the reduced $\mathrm{CO}_{2}$ adsorbate formation. The results derived from these calculations are useful, as a first approximation, to discriminate among possible adsorbates and intermediate species involved in either thermal or electrochemical reduction of $\mathrm{CO}_{2}$ and oxidation of reduced $\mathrm{CO}_{2}$ adsorbates.

\section{Details on the Calculation}

2.1. The Calculation Procedure. The extended Hückel molecular orbital (EHMO) method is the simplest calculation procedure that can be used to describe the valence electronic structure, bonding energy, and chemical properties of relatively large transition metal clusters involved in adsorption problems. Despite its simplicity, it is still the choice when dealing with large systems and high atomic numbers. It has been developed by Hoffmann ${ }^{20,21}$ to study the structural and electronic properties of systems at a frozen geometry. Improvements of this method, mainly related to the addition of two-body electrostatic terms, ${ }^{22-27}$ have made it capable of optimizing the geometry of the adsorbed ensemble within certain

(17) Tayuchi, S.; Ohmori, T.; Aramata, A.; Enyo, M. J. Electroanal. Chem. 1994, 369, 199.

(18) Tayuchi, S.; Aramata, A.; Enyo, M. J. Electroanal. Chem. 1994, $372,161$.

(19) Czerwinski, A.; Sobkowski, J.; Marassi, R. Anal. Lett. 1985, 18 (A-14), 1717.

(20) Hoffmann, R. J. Phys. Chem. 1963, 39, 1797.

(21) Turner, A. G. Methods in Molecular Orbital Theory, PrenticeHall: Englewood Cliffs, N.J., 1974

(22) Anderson, A. B. Surf. Sci. 1981, 105, 159

(23) Anderson, A. B.; Grantscharova, E. J. Phys. Chem. 1995, 99 , 9143; J. Phys. Chem. 1995, 99, 9149.

(24) Estiú, G. L.; Maluendes, S. A.; Castro, E. A.; Arvia, A. J. J. Electroanal. Chem. 1990, 284, 289.

(25) Anders, L. W.; Hansen, R. S.; Bartell, L. S. J. Chem. Phys. 1988 $59,5277$.

(26) Calzaferri, G.; Forss, L.; Kamber, Y. J. Phys. Chem. 1989, 93, 5366.

(27) Braendle, M.; Calzaferri, G. Helv. Chim. Acta 1993, 76, 924. limits. In this framework, the energy of the system, $E_{\mathrm{T}}$, is expressed as

$$
E_{\mathrm{T}}=E_{\mathrm{EHMO}}+\sum_{\mu} b_{\mu}^{\mathrm{o}} \operatorname{VSIP}_{\mu}^{\mathrm{o}}+E_{\mathrm{R}}
$$

where $E_{\mathrm{T}}$ stands for the binding energy of the system, calculated as the difference between the noncorrected EHMO total energy $\left(E_{\text {EHMO }}\right)$ and the addition of the monoelectronic terms that describe the constituents of the system as being infinitely separated and corrected by repulsion. The second term is calculated for the $\mu$ th atomic orbital, by means of the occupation number $\left(\mathrm{b}^{\mathrm{o}}{ }_{u}\right)$ and the valence state ionization potential $\left(\mathrm{VSIP}_{\mu}{ }_{\mu}\right)$, which, in absolute value, equals the diagonal terms of the Hamiltonian (VSIP $\left.=-\mathrm{H}_{i i}\right)$. The correction implies the addition of the repulsion energy term $\left(E_{\mathrm{R}}\right)$ that is evaluated from the contribution of the electrostatic repulsion energies between atoms $\mathrm{A}$ and $\mathrm{B}\left(E_{\mathrm{AB}}\right)$,

$$
E_{\mathrm{R}}=\sum_{\mathrm{A}} \sum_{\mathrm{B}<\mathrm{A}} E_{\mathrm{AB}}
$$

Among the different approaches that have been developed for computing $E_{\mathrm{AB}},{ }^{22-27}$ we prefer to calculate it as the energy difference between the Coulombic interaction of $\mathrm{A}$ and $\mathrm{B}$ separated by a distance $R_{\mathrm{AB}}$ and the arithmetic mean of $\mathrm{A}-\mathrm{B}$ and $\mathrm{B}-\mathrm{A}$ attractive interaction energies. ${ }^{26,27}$

$$
\begin{array}{r}
E_{\mathrm{AB}}=Z_{\mathrm{A}} Z_{\mathrm{B}} / R_{\mathrm{AB}}-1 / 2 Z_{\mathrm{A}} \int \rho_{\mathrm{B}}(r) /\left|R_{\mathrm{A}}-r\right| \mathrm{d} r- \\
1 / 2 Z_{\mathrm{B}} \int \rho_{\mathrm{A}}(r) /\left|R_{\mathrm{B}}-r\right| \mathrm{d} r
\end{array}
$$

where $Z_{i}, R_{i}$, and $\rho_{i}$ are the nuclear charge, position, and electron density of atom $i(i=\mathrm{A}, \mathrm{B})$, B being more electronegative than A. Besides, a distance-dependent exponential factor is also included to correct the offdiagonal EHMO matrix elements, which are calculated by the empirical weighted Wolfsberg-Helmholz formula ${ }^{28}$ applied to the diagonal Hamiltonian and overlap matrix terms

$$
H_{\mu \nu}=1 / 2 K_{\mathrm{AB}}\left(H_{\mu \mu}+H_{v v}\right) S_{\mu \nu}
$$

where $\mu$ and $v$ are the $\mu$ th and the $v$ th orbitals of atoms $\mathrm{A}$ and $\mathrm{B}$, respectively.

$K_{\mathrm{AB}}$ and $\delta$ are adjustable empirical parameters such as $1.4 \leq(1+\kappa) \leq 2.5$ and $0.0 \leq \delta \leq 0.1 \mathrm{~nm}$. They are related by the equation

$$
K_{\mathrm{AB}}=1+\kappa \exp \left[-\delta\left(R_{\mathrm{AB}}-r_{0}\right)\right]
$$

$K_{\mathrm{AB}}$ is the EHMO $K$ parameter used in the off-diagonal Hamiltonian matrix elements, and $r_{0}$ is the sum of atomic radii of $\mathrm{A}$ and $\mathrm{B}$. Other energy matrix elements are kept as in the conventional EHMO methodology.

2.2. The Model. The preceding calculation procedure was extended to describe the interaction of $\mathrm{CO}_{2}$ with $\mathrm{Pt}(111)$ and $\mathrm{Pt}(100)$ cluster surfaces considering the influence of a simulated electric potential and the coadsorption of $\mathrm{H}$-atoms.

High-spin bilayer $\mathrm{Pt}_{\mathrm{N}}$ clusters $(N=25,32)$, with d bands filled with at least one electron per d orbital, were used to model the $\mathrm{Pt}(111)$ and $\mathrm{Pt}(100)$ cluster surfaces, respectively (Figure 1). Clusters were geometrically built, keeping constant the $\mathrm{Pt}-\mathrm{Pt}$ bond length at $0.277 \mathrm{~nm}$, in

(28) Wolfsberg, L.; Helmholz, M. J. Chem. Phys. 1953, 20, 837. 

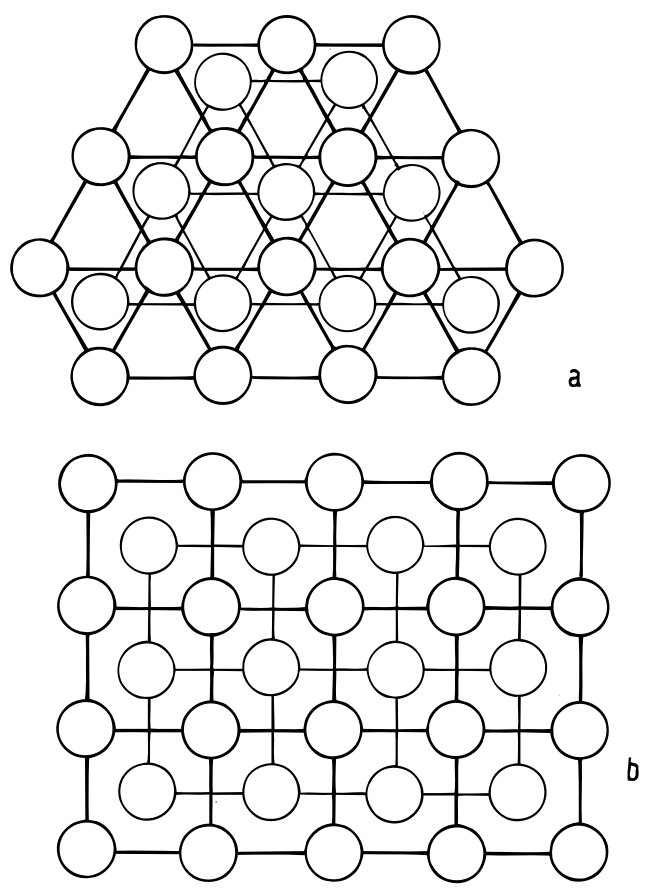

Figure 1. Scheme of the clusters used to model (a) $\mathrm{Pt}(111)$ and (b) $\operatorname{Pt}(100)$.
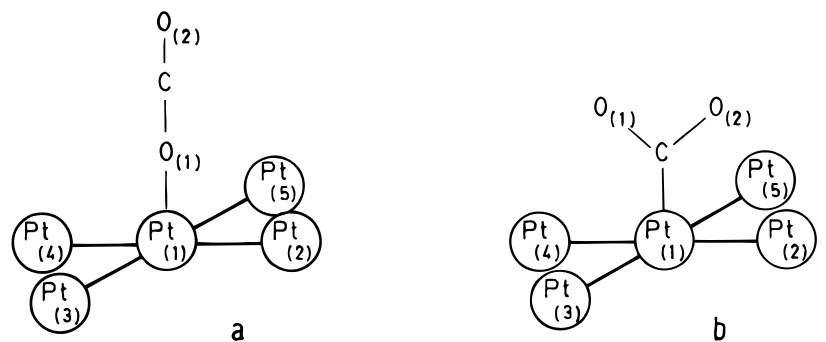

Figure 2. Linear coordination of a $\mathrm{CO}_{2}$ molecule with a $\mathrm{Pt}(100)$ cluster surface (a) bonded through the $\mathrm{O}$ atom and (b) bonded through the $\mathrm{C}$ atom.

agreement with the interatomic distance of bulk Pt. ${ }^{29}$ The multiplicity of the adsorbed ensemble ${ }^{30}$ results from interactions with the close shell $\mathrm{CO}_{2}$ molecule. ${ }^{31-33}$

Coordination of the $\mathrm{CO}_{2}$ molecule with the Pt surface may involve one or two atoms of the adsorbate and one, two, or more atoms of the substrate. When coordination through a single atom from the adsorbate is considered, the occupation of different $\mathrm{Pt}$ adsorption sites defines several adsorption configurations on each Pt cluster, i.e., linear on-top (1-fold), bridge (2-fold), and hollow (higher coordinated sites). Hollow sites are associated with a 5 -fold coordination of the adsorbate on $\mathrm{Pt}(100)$ (four $\mathrm{Pt}$ atoms of the topmost layer and one $\mathrm{Pt}$ atom from the underlying layer). For Pt(111), either three or four $\mathrm{Pt}$ atoms may define either the $(3-1)$ - or $(3-3)$-hollow coordination site, depending on the local symmetry of the adsorbate. For each case, the coordination through either the $\mathrm{C}$ or the $\mathrm{O}$ atom is considered (Figure 2). When two adsorbate atoms are involved in the coordination, two adsorbed species are distinguished, namely, the formate species, which is bound directly through two $\mathrm{O}$ atoms

(29) Lide, D. R., Ed. CRC Handbook of Chemistry and Physics; CRC Press: Boca Raton, FL., 1990-91.

(30) Zinola, C. F.; Estiú, G. L.; Castro, E. A.; Arvia, A. J. J. Phys Chem. 1994, 98, 1766

(31) Jeung, G. H. Mol. Phys. 1988, 65, 669

(32) Jeung, G. H. Mol. Phys. 1989, 67, 747.

(33) Jeung, G. H. Chem. Phys. Lett. 1995, 232, 319.

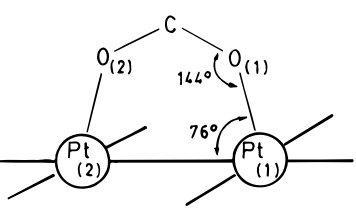

a

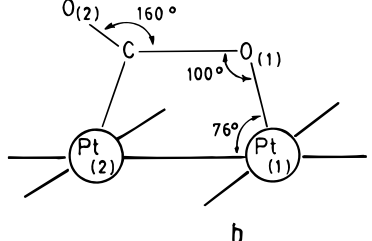

Figure 3. Adsorbate geometries resulting from a two-atom $\mathrm{CO}_{2}$ coordination on a $\mathrm{Pt}(100)$ surface: (a) formate adsorbate; (b) side-on $\mathrm{CO}_{2}$ adsorbate.

Table 1. EHMO Calculation: Optimized Parameters Based on $\mathrm{Pt}-\mathrm{O}$ Bond

\begin{tabular}{crcccc}
\hline atomic orbital & \multicolumn{1}{c}{$\mathrm{VSIP}^{a} \mathrm{eV}$} & $\zeta_{1}{ }^{b}$ & $\zeta_{2}{ }^{b}$ & $\mathrm{c}_{1}{ }^{c}$ & $c_{2}{ }^{c}$ \\
\hline Pt 5d & 12.83 & 4.0950 & 1.8600 & 0.7980 & 0.3520 \\
Pt 6s & 9.32 & 1.9830 & & & \\
Pt 6p & 5.72 & 1.3440 & & & \\
C 2s & 21.85 & 2.1600 & & & \\
C 2p & 11.85 & 2.0750 & & & \\
O 2s & 27.96 & 2.5640 & & & \\
O 2p & 12.16 & 2.2640 & & & \\
H 1s & 13.50 & 1.3000 & & &
\end{tabular}

${ }^{a}$ VSIP $\equiv$ valence state ionization potential. ${ }^{b} \xi_{1,2} \equiv$ orbital exponents of the base generating functions. ${ }^{c} c_{1,2} \equiv$ linear coefficients of the double zeta Pt d-orbitals.

Table 2. EHMO Calculation: Optimized Parameters Based on $\mathrm{Pt}-\mathrm{C}$ Bond

\begin{tabular}{crcccc}
\hline atomic orbital & $\mathrm{VSIP},{ }^{a} \mathrm{eV}$ & $\zeta_{1}{ }^{b}$ & $\zeta_{2}{ }^{b}$ & $c_{1}{ }^{c}$ & $c_{2}{ }^{c}$ \\
\hline Pt $5 \mathrm{~d}$ & 13.33 & 4.8950 & 2.3600 & 1.2980 & 0.8520 \\
Pt 6s & 9.82 & 2.4830 & & & \\
Pt 6p & 7.22 & 2.8440 & & & \\
C 2s & 22.35 & 2.6600 & & & \\
C 2p & 12.35 & 2.5750 & & & \\
O 2s & 28.46 & 3.0640 & & & \\
O 2p & 12.66 & 2.7640 & & & \\
H 1s & 14.00 & 1.8000 & & &
\end{tabular}

${ }^{a}$ VSIP $\equiv$ valence state ionization potential. ${ }^{b} \xi_{1,2} \equiv$ orbital exponents of the base generating functions. ${ }^{c} c_{1,2} \equiv$ linear coefficients of the double zeta Pt d-orbitals.

(Figure 3a), and the side-on $\mathrm{CO}_{2}$ species, which is bound through one $\mathrm{C}$ atom and one $\mathrm{O}$ atom (Figure $3 \mathrm{~b}$ ).

Equilibrium VSIP values are evaluated in the way previously proposed by Anderson. ${ }^{23}$ To consider the polarization of the substrate surface by the $\mathrm{CO}_{2}$ molecule, the VSIP and Slater exponents are changed until the calculated charges on the atoms for the diatomic bond are close to those predicted by the electronegativity difference resulting from the Pauling's ionicity relationship. ${ }^{34}$ This approach has been extensively applied to the study of electrochemical systems. ${ }^{35-40}$

Coordination of $\mathrm{CO}_{2}$ through either the $\mathrm{C}$ or $\mathrm{O}$ atom would imply a different polarization of the surface. Different values of VSIP and Slater orbital exponents define, thence, the reference potential of the $\mathrm{CO}_{2}-\mathrm{Pt}$ system for coordinations through the $\mathrm{C}$ atom (Table 1) and the $\mathrm{O}$ atom (Table 2). Values $K_{\mathrm{AB}}=1.75$ and $\delta=$ 0.035 render an appropriate description of the equilibrium distances and associated energies with the set of param-

(34) Pauling, L. The Nature of the Chemical Bond, 3rd ed.; Cornell University Press: Ithaca, NY, 1992; p 45.

(35) Anderson, A. B.; Awad, M. K. J. Am. Chem. Soc. 1985, 107, 7854 .

(36) Anderson, A. B.; Ray, N. K. J. Phys. Chem. 1982, 86, 488

(37) Anderson, A. B. J. Electroanal. Chem. 1990, 280, 37.

(38) López, M. B.; Estiú, G. L.; Castro, E. A.; Arvia, A. J. J. Mol. Struct. (THEOCHEM). 1990, 210, 353.

(39) Estiú, G. L.; Maluendes, S. A.; Castro, E. A.; Arvia, A. J. J. Phys Chem. 1986, 92, 2512

(40) Mehandru, S. P.; Anderson, A. B. J. Phys. Chem. 1989, 93, 2044 
a

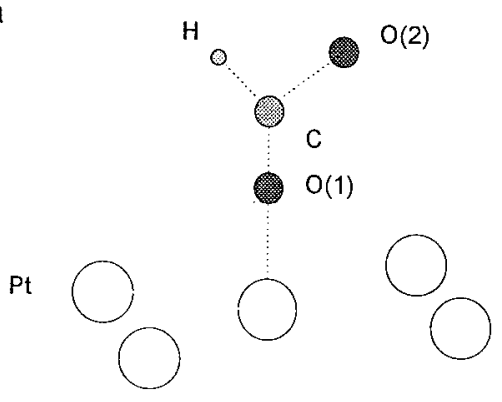

c

Pt<smiles>C1CCCCCC1</smiles><smiles>OOC(O)Oc1ccccc1</smiles>

e

$O(2)$

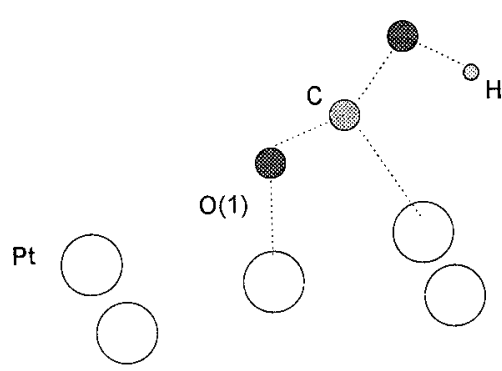

b<smiles>C1CCCC1</smiles>

$\mathrm{Pt}$

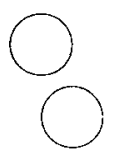

d

$\mathrm{Pt}$
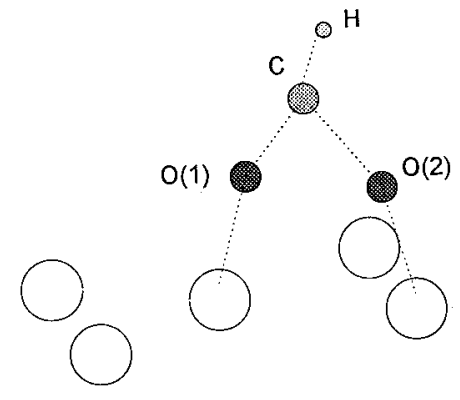

f
$\mathrm{Pt}$

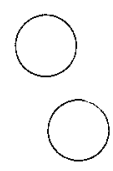

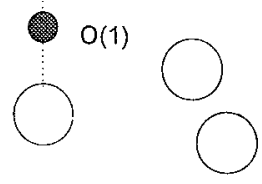

O $\mathrm{O}(2)$

$0^{\mathrm{C}}$

$\mathrm{H}$

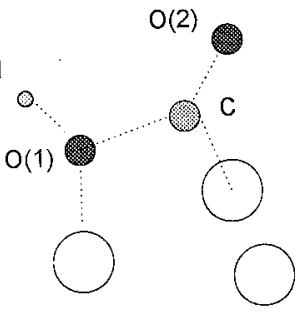

g

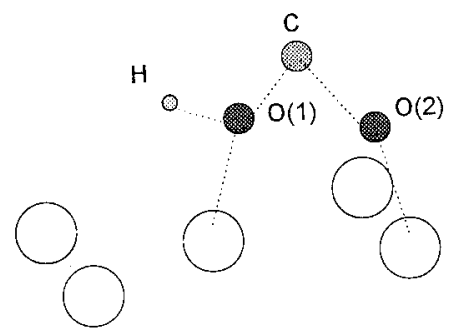

Figure 4. Different $\mathrm{CO}_{2} \cdot \mathrm{H}$ adsorbate configurations on a $\mathrm{Pt}(100)$ surface: (a) $\mathrm{H}-\mathrm{C}$ atom coordination; (b) $\mathrm{H}-\mathrm{O}(2)$ atom coordination; (c) $\mathrm{H}-\mathrm{O}(1)$ atom coordination; (d) hydrogenated formate adsorbate resulting from bending the $\mathrm{O}(1)-\mathrm{C}-\mathrm{O}(2)$ angle toward a neighbor Pt atom; (e) side on $\mathrm{H}-\mathrm{O}(2) \mathrm{CO}$ adsorbate resulting from bending the $\mathrm{O}(1)-\mathrm{C}-\mathrm{O}(2)$ angle toward a neighbor $\mathrm{Pt}$ atom; (f) side on $\mathrm{H}-\mathrm{O}(1) \mathrm{CO}$ adsorbate resulting from bending the $\mathrm{O}(1)-\mathrm{C}-\mathrm{O}(2)$ angle toward a neighbor Pt atom; (g) hydrogenated formate adsorbate with the $\mathrm{H}$ atom bound to one $\mathrm{O}$ atom.

eters assembled in Tables 1 and 2. When coordination is accomplished through both the $\mathrm{C}$ and $\mathrm{O}$ atoms simultaneously, the polarization induced by the $\mathrm{O}$ atom has been considered in the calculations, as it always renders the most stable structures. For $\mathrm{CO}_{2}$ and $\mathrm{H}$ coadsorption, both species also contribute to modify the electronic density of the Pt surface and, accordingly, the VSIP. Because experimental data on the formation and characteristics of the stable structure of the $\mathrm{CO}_{2}-\mathrm{H}$ coadsorbate on $\mathrm{Pt}$ are not perfectly known, we have chosen a model that considers the influence of $\mathrm{H}$ atoms interacting with adsorbed $\mathrm{CO}_{2}$ and the surface polarized, thence, by the latter. In this way, the surface polarization induced by the $\mathrm{CO}_{2}$ molecule and $\mathrm{H}$ atom is taken into account by comparing the $\mathrm{CO}_{2}$ and $\mathrm{CO}_{2}{ }^{\circ} \mathrm{H}$ adsorption without further changes in the physical model.
The applied electric potential is simulated by changing the Fermi energy level of Pt, either decreasing or increasing the absolute value of $V S I P$, from the reference value taken as the potential of zero charge (pzc) of Pt (Table 1), leading to a negative or a positive metal surface charge, respectively. ${ }^{23}$ Considering the accuracy of the results obtained in previous investigations, ${ }^{23,35,36}$ the correlation between the VSIP shift and the simulated electric potential has been set as $1(1 \mathrm{~V} \equiv 1 \mathrm{eV})$.

The geometry of reduced $\mathrm{CO}_{2}$ adsorbates has been fully optimized to minimum energy in each case. This implies the simultaneous modification of bond lengths and planar and dihedral angles. Thus, the $\mathrm{C}-\mathrm{O}(1)$ distance $\left(r_{\mathrm{O}(1) \mathrm{C}}\right)$ (Figures 2-4) has been varied stepwise in $0.001 \mathrm{~nm}$ until minimum energy was attained. For each fixed value of 
Table 3. Binding Energy (BE), Repulsion Energy (ER), Optimized Interatomic Distance $\left(r_{\mathrm{A}-\mathrm{B}}\right)$, and Net Atomic Charge $(q A)$ Values Resulting from Calculations for $\left[\mathrm{Pt}(111)^{\circ} \mathrm{O}(1) \mathrm{CO}(2)\right]$ and $\left[\mathrm{Pt}(100)^{\cdot} \mathrm{O}(1) \mathrm{CO}(2)\right]$ at the Reference Potential

\begin{tabular}{|c|c|c|c|c|c|c|c|c|c|c|}
\hline & BE, eV & $E_{\mathrm{R}}, \mathrm{eV}$ & $r_{\mathrm{Pt}-\mathrm{O}_{1}}, \mathrm{~nm}$ & $r_{\mathrm{O}_{1}-\mathrm{C}}, \mathrm{nm}$ & $r_{\mathrm{C}-\mathrm{O}_{2}}, \mathrm{~nm}$ & $q_{\mathrm{Pt}}, \mathrm{eu}$ & $q_{\mathrm{Pt}}, \mathrm{eu}$ & $q_{\mathrm{O}_{1}}$, eu & $q_{\mathrm{C}}, \mathrm{eu}$ & $q_{\mathrm{O}_{2}} \mathrm{eu}$ \\
\hline \multicolumn{11}{|c|}{$\operatorname{Pt}(111)$} \\
\hline on-top & -0.7416 & 7.30 & 0.174 & 0.152 & 0.110 & & 0.89 & 0.18 & 0.02 & -0.03 \\
\hline bridge & -0.1679 & 7.54 & 0.213 & 0.127 & 0.108 & & 1.21 & 1.02 & 0.01 & 0.76 \\
\hline $\begin{array}{l}\text { hollow } \\
(3-3)\end{array}$ & 0.0086 & 10.55 & 0.154 & 0.116 & 0.210 & & & 1.52 & -0.96 & -1.31 \\
\hline $\begin{array}{l}\text { hollow } \\
(3-1)\end{array}$ & 0.0559 & 13.36 & 0.158 & 0.120 & 0.210 & & -0.30 & 1.11 & -0.92 & -1.30 \\
\hline side-on & -3.0184 & 8.34 & 0.165 & 0.228 & 0.109 & $0.45^{a}$ & 0.72 & 0.05 & -0.13 & 0.10 \\
\hline formate & -1.4674 & 8.01 & 0.194 & 0.120 & 0.120 & & 0.98 & 0.34 & -0.23 & 0.13 \\
\hline \multicolumn{11}{|c|}{$\operatorname{Pt}(100)$} \\
\hline on-top & -1.3817 & 7.50 & 0.185 & 0.155 & 0.110 & & 2.03 & 0.94 & 0.25 & 0.51 \\
\hline bridge & -1.1885 & 7.34 & 0.204 & 0.159 & 0.105 & & 1.32 & 0.60 & 0.04 & 1.06 \\
\hline hollow & 1.0405 & 7.13 & 0.185 & 0.175 & 0.110 & & 0.41 & 1.84 & -0.86 & -1.18 \\
\hline side-on & -3.4305 & 8.12 & 0.184 & 0.191 & 0.112 & $0.34^{a}$ & 0.82 & -0.05 & -0.28 & 0.26 \\
\hline formate & -2.0497 & 7.90 & 0.183 & 0.120 & 0.120 & & 1.12 & 0.11 & -0.12 & 0.11 \\
\hline
\end{tabular}

${ }^{a} q_{\mathrm{Pt}}$ is the charge of the $\mathrm{Pt}$ bound to $\mathrm{C}$ atom in side-on coordination.

$r_{\mathrm{O}(1) \mathrm{C}}$ the remaining internal coordinates were fully optimized.

Adsorption energies (binding energies, BE) were calculated as the difference:

$$
\mathrm{BE}=E_{\mathrm{T}, \mathrm{PtN} . \mathrm{X}}-E_{\mathrm{T}, \mathrm{PtN}}-E_{\mathrm{T}, \mathrm{X}}
$$

where $E_{\mathrm{T}, \mathrm{PtN}}$ and $E_{\mathrm{T}, \mathrm{PtN} . \mathrm{X}}$ stand for the total energy of the $\left[\mathrm{Pt}_{\mathrm{N}}\right]$ and $\left[\mathrm{Pt}_{\mathrm{N} \cdot \mathrm{X}}\right]\left(\mathrm{X}=\mathrm{CO}_{2}, \mathrm{CO}_{2} \cdot \mathrm{H}\right)$ cluster.

It should be noted that the energy values resulting from semiempirical calculations are not absolute but relative values. They should be considered to analyze trends in the variation of the energy according to modifications produced in the system by changing a variable such as, for instance, the applied electric potential. The parametric condition of the semiempirical procedures led to an overestimation of the binding energy values. It is not only the case of EH calculations, but it is also well-known for neglect of differential overlap (NDO) methodologies, which result in $\mathrm{BE}$ values that have to be corrected according to experimental data. ${ }^{41}$

In our case, $\mathrm{BE}$ data can be compared to the $\mathrm{CO}_{2}-\mathrm{Pt}$ experimental adsorption energy by subtracting $2 \mathrm{eV}$. The energy scale was normalized considering the $\mathrm{BE}$ of $\mathrm{CO}-$ Pt calculated by the same procedure, $3.2 \mathrm{eV},{ }^{42}$ and the $\mathrm{CO}-\mathrm{Pt}$ experimental adsorption energy, which is close to $1.2 \mathrm{eV}^{43}$

\section{Results}

3.1. The Interaction of a Single $\mathrm{CO}_{2}$ Molecule with Pt(111) and Pt(100) Cluster Surfaces. The equilibrium $\mathrm{C}-\mathrm{O}$ bond length, $r_{\mathrm{CO}}=0.118 \mathrm{~nm}$, calculated for free $\mathrm{CO}_{2}$ is close to the experimental value, ${ }^{29}$ that is, $0.120 \mathrm{~nm}$, whereas the calculated dissociation energy is $-5.6963 \mathrm{eV}$, a figure that exceeds published data by $1.6 \mathrm{eV} .{ }^{29}$ However, despite this difference, the optimized geometry resulting from the calculation is very accurate. As the semiempirical method is limited for energy value calculations because of their large dependence on the parametrization, attention is focused on the calculated geometries.

3.1.1. $\mathrm{CO}_{2}$ Adsorption through One Adsorbate Atom. The adsorption of $\mathrm{CO}_{2}$ on $\mathrm{Pt}(111)$ and $\mathrm{Pt}(100)$ cluster surfaces involving one atom of $\mathrm{CO}_{2}$ was studied

(41) Estiú, G. L.; Zerner, M. C. Int. J. Quantum Chem. 1992, 26, 587. (42) Paredes Olivera, P.; Estiú, G. L.; Castro, E. A.; Arvia, A. J. J. Mol. Struct. 1990, 210, 393.

(43) Campuzano, J. C. In The Chemical Physics of Solid Surfaces and Heterogeneous Catalysis; King, D. A., Woodfrusff, D. P., Eds.; Chemisorption Systems, Part A, Elsevier Science Publishers: Amsterdam-New York, 1990; Vol. 3, Chapter 4, p 453. for the molecule bound to $\mathrm{Pt}$ through either the $\mathrm{C}$ or $\mathrm{O}$ atom, considering for each case the on-top (1-fold), bridge (2-fold), and hollow (multi)-coordination.

In contrast to the adsorption of $\mathrm{CO}_{2}$ on $\mathrm{Pt}$ through the $\mathrm{C}$ atom, which always results in a positive value of $\mathrm{BE}$, that is, no stable adsorbate is formed, the adsorption through the $\mathrm{O}$ atom leads to stable $\mathrm{CO}_{2}$ adsorbates.

The geometric characteristics and $\mathrm{BE}$ values for stable O-bonded adsorbates are assembled in Table 3. These data show that the linear (on-top) $\mathrm{CO}_{2}$ adsorption is favored on both $\mathrm{Pt}(111)$ and $\operatorname{Pt}(100)$ cluster surfaces at the reference potential, as earlier reported by Anderson et al. ${ }^{44}$

For both $\mathrm{Pt}(100)$ and $\mathrm{Pt}(111)$ cluster surfaces, the ontop adsorption of $\mathrm{CO}_{2}$ implies the stretching of the $\mathrm{O}(1)-\mathrm{C}$ bond by $0.03 \mathrm{~nm}$ (Figure 2), resulting in a strained $\mathrm{C}-\mathrm{O}(1)$ single bond. ${ }^{29}$ With this stretched bond length fixed, configurations with a tilting of the $\mathrm{O}(1)-\mathrm{C}-\mathrm{O}(2)$ planar angle between $0^{\circ}$ and $30^{\circ}$ define isoenergetic adsorbates. This result is in agreement with the ab initio calculations about the interaction of $\mathrm{CO}_{2}$ with a single transition metal atom recently reported by Jeung. ${ }^{33}$

A molecular orbital analysis shows that both the $\sigma$ and $\pi$ orbitals of the on-top $\mathrm{CO}_{2}$ adsorbate are involved in bonding interactions with the $\mathrm{d}$ atomic orbitals of adjacent Pt atoms. Then, the $\mathrm{CO}_{2}$ adsorption bond on both $\mathrm{Pt}(100)$ and $\mathrm{Pt}(111)$ cluster surfaces can be described as a charge transfer from $\mathrm{CO}_{2}$ to the Pt cluster, involving a $\sigma$-bond reinforced by a $\pi$-type $\mathrm{Pt}(1)-\mathrm{O}(1)$ bond delocalized toward the adjacent $\mathrm{O}(1)-\mathrm{C}$ bond. However, although an electron transfer from $\mathrm{CO}_{2}$ to $\mathrm{Pt}(1)$ occurs, the $\mathrm{Pt}$ atom remains positively charged, as the transferred electron charge is spread throughout the entire Pt cluster. In this case, the $\mathrm{O}(2)$ atom is scarcely involved in the adsorption bond, its coordination being mainly related to the extended $\pi$-type interaction. Hence, according to the bond distances (Table 3 ), the $\mathrm{O}(1)-\mathrm{C}$ bond changes from a double to a single bond because of charge donation. It should be noted that ab initio calculations which describe the $\mathrm{CO}_{2}-\mathrm{Pt}$ adsorption interaction defining the metal side by a single $\mathrm{Pt}$ atom, ${ }^{33}$ also found an ionic character of the bond but a charge transfer from Pt to $\mathrm{CO}_{2}$. These results are affected to some extent by the absence of Pt interacting atoms, which, without the application of embedding techniques, precludes the spreading of charge over the metal cluster.

The bridge $\mathrm{CO}_{2}$ adsorbate on both $\mathrm{Pt}(100)$ and $\mathrm{Pt}(111)$ cluster surfaces involves two Pt atoms interacting with the $\mathrm{CO}_{2}$ molecule. As the $\mathrm{Pt}-\mathrm{O}$ bond length is larger

(44) Ray, N. K.; Anderson, A. B. Surf. Sci. 1982, 119, 35. 
Table 4. Binding Energy (BE) Values at Different Simulated Electric Potentials for Adsorbates Resulting from One Atom $\mathrm{CO}_{2}$ Coordination on $\mathrm{Pt}(111)$ and $\mathrm{Pt}(100)$

$\operatorname{Pt}(100)$

\begin{tabular}{crcrcc}
\hline potential & \multicolumn{1}{c}{ on-top } & bridge & hollow & side-on & formate \\
\hline 1.0 & -0.5156 & -0.3639 & 1.8964 & -6.9113 & -5.1158 \\
0.8 & -0.6649 & -0.4543 & 1.7052 & -6.0131 & -4.6831 \\
0.6 & -0.8543 & -0.6769 & 1.5131 & -5.6457 & -3.9757 \\
0.4 & 1.0904 & -0.8849 & 1.3868 & -4.8322 & -3.4321 \\
0.2 & -1.2015 & -1.0021 & 1.2043 & -4.0132 & -2.0497 \\
0 & -1.3817 & -1.1885 & 1.0405 & -3.4305 & -2.0497 \\
-0.2 & -2.1519 & -1.9490 & 0.5016 & -3.8681 & -2.1649 \\
-0.4 & -2.8986 & -2.7050 & 0.2143 & -4.1516 & -2.2751 \\
-0.6 & -3.2526 & -3.2119 & -0.0191 & -4.4452 & -2.3627 \\
-0.8 & -3.8020 & -3.8476 & -0.4543 & -4.8983 & -2.4331 \\
-1.0 & -4.1600 & -4.3519 & -0.8980 & -5.0844 & -2.5662
\end{tabular}

$\operatorname{Pt}(111)$

\begin{tabular}{ccccccc}
\hline potential & on-top & bridge & $\begin{array}{c}\text { hollow- } \\
(3-1)\end{array}$ & $\begin{array}{c}\text { hollow- } \\
(3-3)\end{array}$ & side-on & formate \\
\hline 1.0 & -0.3046 & -0.1459 & 1.5634 & 1.3452 & -5.6775 & -4.5757 \\
0.8 & -0.3678 & -0.1467 & 1.3467 & 1.0347 & -5.0131 & -4.0341 \\
0.6 & -0.4247 & -0.1478 & 1.1378 & 0.8734 & -4.8751 & -3.7757 \\
0.4 & -0.5467 & -0.1519 & 0.8543 & 0.5523 & -4.1254 & -2.9872 \\
0.2 & -0.6154 & -0.1537 & 0.2043 & 0.2189 & -3.6732 & -2.2561 \\
0 & -0.7416 & -0.1679 & 0.0559 & 0.0086 & -3.0184 & -1.4674 \\
-0.2 & -1.4534 & -0.9278 & -0.2466 & -0.2239 & -3.7681 & -1.6336 \\
-0.4 & -2.0478 & -1.6781 & -0.4557 & -0.3345 & -4.1021 & -1.8248 \\
-0.6 & -2.7681 & -2.3467 & -0.5931 & -0.5432 & -4.3458 & -1.9072 \\
-0.8 & -3.8341 & -3.9341 & -0.7183 & -0.7345 & -4.4917 & -2.0982 \\
-1.0 & -4.5224 & -4.3519 & -0.8980 & -1.0945 & -4.6263 & -2.1212 \\
& & & & & &
\end{tabular}

than that in the 1-fold coordination, a less effective charge transfer from $\mathrm{CO}_{2}$ to the Pt cluster occurs, resulting in a less stable adsorbate (Table 3 ).

The adsorptive $\mathrm{CO}_{2}-\mathrm{Pt}$ interaction at both (3-3)- and (3-1)-hollow sites implies a substantial contribution of repulsive interactions, and accordingly, the calculated values of BE correspond to unstable adsorbates (Table 3).

Let us consider the influence of the Pt cluster polarization by an external potential on the value of BE. Data assembled in Table 4 show that, regardless the geometry and topology of the surface, the adsorption is favored by negatively charging. The effect becomes more relevant for the bridge coordination, which reverses the stability relative to on-top for values close to $-1.0 \mathrm{~V}$ on $\mathrm{Pt}(100)$.

The (3-3)- and (3-1)-hollow $\mathrm{CO}_{2}$ adsorbates remain unstable for simulated electric potentials higher than -0.8 $\mathrm{V}$ for $\mathrm{Pt}(100)$ and $-0.4 \mathrm{~V}$ for $\mathrm{Pt}(111)$ (Table 4). These adsorbates are less stable than the on-top and bridge adsorbates even at $-1.0 \mathrm{~V}$ on both Pt cluster surfaces. The fact that the adsorption of $\mathrm{CO}_{2}$ on $\mathrm{Pt}$ is favored when Pt clusters are negatively charged agrees with the experimental data derived from the necessity of covering the $\mathrm{H}$-adatom potential region for the $\mathrm{CO}_{2}$ adsorption. $8,9,11,12$

Both the $\mathrm{Pt}-\mathrm{O}(1)$ and $\mathrm{O}(1)-\mathrm{C}$ bond lengths decrease as the applied potential is negatively shifted, because the charge transfer becomes less effective. These changes in bond length have a negligible influence on the $\mathrm{C}-\mathrm{O}(2)$ bond over the -1.0 to $1.0 \mathrm{~V}$ simulated electric potential range. For bridge $\mathrm{CO}_{2}$ adsorbates, the value of the $\mathrm{O}(1)-$ $\mathrm{Pt}-\mathrm{Pt}$ angle changes from $66^{\circ}$ to $58^{\circ}$ for $\mathrm{Pt}(100)$, and from $68^{\circ}$ to $57^{\circ}$ for $\mathrm{Pt}(111)$ when the simulated electric potential goes from 1.0 to $-1.0 \mathrm{~V}$. Simultaneously, the value of the $\mathrm{Pt}-\mathrm{O}(1)-\mathrm{C}$ angle varies from $114^{\circ}$ to $122^{\circ}$ on $\mathrm{Pt}(100)$ and from $112^{\circ}$ to $123^{\circ}$ on $\operatorname{Pt}(111)$, by changing the simulated electric potential within the same range. The optimized geometric parameters of $\mathrm{CO}_{2}$ adsorbates on both Pt cluster surfaces at different applied potentials are available upon request.
3.1.2. $\mathrm{CO}_{2}$ Coordination through Two Adsorbate Atoms. When the adsorption of $\mathrm{CO}_{2}$ on $\mathrm{Pt}$ involves two adsorbate atoms, two species can be formed, namely, a formate adsorbed species that is bound directly through two $\mathrm{O}$ atoms (Figure 3a) and a side-on $\mathrm{CO}_{2}$ species that is bound through the $\mathrm{C}$ and one $\mathrm{O}$ atom (Figure $3 \mathrm{~b}$ ). Formate adsorbates have been experimentally detected on metal surfaces by means of spectroscopic techniques, ${ }^{1}$ whereas the existence of side-on adsorbates has been concluded from infrared emission spectroscopy during hydrocarbon oxidations on Pt. ${ }^{45}$

Binding energy data for formate and side-on $\mathrm{CO}_{2}$ adsorbates on the $\mathrm{Pt}(100)$ and $\mathrm{Pt}(111)$ cluster surfaces are assembled in Table 3. For both adsorbates, the BE values depend on the applied potential, defining minimun stabilization at $0 \mathrm{~V}$. However, regardless of the simulated potential, side-on $\mathrm{CO}_{2}$ adsorbates become the most stable ones on both Pt cluster surfaces. Data assembled in Table 4 show that the stabilization of the side-on $\mathrm{CO}_{2}$ adsorbate on $\operatorname{Pt}(100)$ is always substantially higher than that on $\mathrm{Pt}(111)$, and the corresponding BE differences decrease as the applied potential is negatively shifted.

As previously mentioned, the greatest stability of the adsorbates at $1.0 \mathrm{~V}$ is due to a charge transfer from $\mathrm{CO}_{2}$ to $\mathrm{Pt}$, which results in a charge on the molecule that is around +0.36 for the $\operatorname{Pt}(111)$ surface and +0.6 for the $\mathrm{Pt}(100)$ surface. The reverse charge-transfer process is responsible of the stabilization at $-1.0 \mathrm{~V}$. This is reflected in a negative charge for the adsorption of $\mathrm{CO}_{2}$ on Pt which is again larger for $\mathrm{Pt}(100)(-0.53)$ than for Pt111) $(-0.17)$. These figures justify, also, the larger stabilization on the $\operatorname{Pt}(100)$ surfaces.

3.2. The Interaction of a Single $\mathrm{CO}_{2}$ Molecule with the Pt(111) and Pt(100) Cluster Surface in the Presence of $\mathbf{H}$ Atoms. The influence of a $\mathrm{H}$ atom of the environment on the stabilization of $\mathrm{CO}_{2}$ adsorbates has been extensively discussed in relation to the mechanism of $\mathrm{CO}_{2}$ electrooxidation on Pt. ${ }^{1-5,9-14}$ Therefore, the calculation procedure previously described was extended to determine the geometry and $\mathrm{BE}$ values of the most likely adsorbates that might result from the coadsorption of $\mathrm{CO}_{2}$ and $\mathrm{H}$ on $\mathrm{Pt}(100)$ and $\mathrm{Pt}(111)$ cluster surfaces. In this way, the occupation of on-top, bridge, and hollow sites by $\mathrm{H}$ and on-top, bridge, hollow, side-on, and formate sites by $\mathrm{CO}_{2}$ have been considered simultaneously, to compare the binding energies of the different resulting $\mathrm{CO}_{2} \cdot \mathrm{H}$ adsorbates as well as their evolution under the influence of an applied electric potential. In all the cases, full geometry optimizations were performed in order to find out the characteristics of the most stable adsorbed structures. The results from these calculations are assembled, for the uncharged surfaces, in Table 5.

Coadsorption of hydrogen with formate species define the most stable structures on both Pt surfaces, followed by the system associated with the on-top coordination of both adsorbates. For these, most stable structures, the coordination of $\mathrm{H}$ with a $\mathrm{Pt}$ atom adjacent to $\mathrm{CO}_{2}$ has been compared with the direct coordination to either the $\mathrm{C}$ or $\mathrm{O}$ atoms of the adsorbed $\mathrm{CO}_{2}$ molecule (Figure 4). For both the formate and the on-top linear $\mathrm{CO}_{2}$ coordinations, the direct bonding of $\mathrm{H}$ to the $\mathrm{C}$ atom of the adsorbed molecule stabilizes the system relative to the adjacent adsorption of both species. In the case of formate, the system is stabilized in $1.0 \mathrm{eV}$ on $\mathrm{Pt}(100)$ and $0.6 \mathrm{eV}$ on $\mathrm{Pt}(111)$ by hydrogen migration to the $\mathrm{C}$ atom of the $\mathrm{CO}_{2}$ molecule, whereas for the case of linear coordination the

(45) Uetsuka, H.; Watanabe, K.; Iwade, T.; Kunimori, K. J. Chem Soc., Faraday Trans. 1995, 91, 1801. 
Table 5. Values of $\mathrm{BE}$ for $\mathrm{CO}_{2}$ and $\mathrm{H}$ Adsorbates on Pt(111) and Pt(100) at the Reference Potential

\begin{tabular}{|c|c|c|c|c|c|}
\hline \multicolumn{3}{|c|}{$\operatorname{Pt}(100)$} & \multicolumn{3}{|c|}{$\operatorname{Pt}(111)$} \\
\hline H-atom & $\mathrm{CO}_{2}$ & $\mathrm{BE} / \mathrm{eV}$ & H-atom & $\mathrm{CO}_{2}$ & $\mathrm{BE} / \mathrm{eV}$ \\
\hline on-top & on-top & -3.0129 & on-top & on-top & -2.4560 \\
\hline on-top & bridge & -2.8567 & on-top & bridge & -2.2324 \\
\hline on-top & hollow & -1.9786 & on-top & hollow $(3-3)$ & -1.0954 \\
\hline on-top & formate & -3.5589 & on-top & hollow $(3-1)$ & -1.0002 \\
\hline on-top & side-on & -2.6651 & on-top & formate & -3.4254 \\
\hline & & & on-top & side-on & -2.4123 \\
\hline bridge & on-top & -2.9929 & bridge & on-top & -2.3456 \\
\hline bridge & bridge & -2.7547 & bridge & bridge & -2.1325 \\
\hline bridge & hollow & -1.6723 & bridge & hollow $(3-3)$ & -0.9456 \\
\hline bridge & formate & -3.4531 & bridge & hollow $(3-1)$ & -0.8751 \\
\hline bridge & side-on & -2.3197 & bridge & formate & -3.3278 \\
\hline & & & bridge & side-on & -2.1966 \\
\hline hollow & on-top & -1.7531 & hollow $(3-1)$ & on-top & -1.5623 \\
\hline hollow & bridge & -1.5673 & hollow $(3-1)$ & bridge & -1.1211 \\
\hline hollow & hollow & -0.3489 & hollow $(3-1)$ & hollow $(3-3)$ & -0.3632 \\
\hline hollow & formate & -2.0146 & hollow $(3-1)$ & hollow $(3-1)$ & -0.1435 \\
\hline hollow & side-on & -1.8831 & hollow $(3-1)$ & formate & -1.9433 \\
\hline & & & hollow $(3-1)$ & side-on & -1.7675 \\
\hline & & & hollow $(3-3)$ & on-top & -1.2378 \\
\hline & & & hollow $(3-3)$ & bridge & -0.9864 \\
\hline & & & hollow $(3-3)$ & hollow $(3-3)$ & 0.0123 \\
\hline & & & hollow $(3-3)$ & hollow $(3-1)$ & 0.0924 \\
\hline & & & hollow $(3-3)$ & formate & 0.1029 \\
\hline & & & hollow $(3-3)$ & side-on & 0.4099 \\
\hline
\end{tabular}

Table 6. Values of BE for CO2.H Adsorbates on Pt(111) and Pt(100) Surfaces at the Reference Potential

\begin{tabular}{ccccccc}
\hline \multicolumn{3}{c}{$\mathrm{Pt}(100)$} & & & \multicolumn{3}{c}{$\mathrm{Pt}(111)$} \\
\cline { 1 - 1 } H-atom & $\mathrm{CO}_{2}$ & $\mathrm{BE} / \mathrm{eV}$ & & H-atom $\mathrm{CO}_{2}$ & $\mathrm{BE} / \mathrm{eV}$ \\
\hline on-top on-top & -3.0129 & & on-top on-top & -2.4560 \\
$\mathrm{H}-\mathrm{CO}_{2}(\mathrm{f})$ & -4.5782 & & $\mathrm{H}-\mathrm{CO}_{2}(\mathrm{f})$ & -4.1233 \\
$\mathrm{H}-\mathrm{O}(2) \mathrm{CO}(\mathrm{t})$ & -2.8431 & & $\mathrm{H}-\mathrm{O}(2) \mathrm{CO}(\mathrm{t})$ & -2.2143 \\
$\mathrm{H}-\mathrm{O}(1) \mathrm{CO}(\mathrm{t})$ & -2.9973 & & $\mathrm{H}-\mathrm{O}(1) \mathrm{CO}(\mathrm{t})$ & -2.2241 \\
on-top formate & -3.5589 & & on-top formate & -3.4254 \\
$\mathrm{H}-\mathrm{OCO}(\mathrm{f})$ & -3.1192 & & $\mathrm{H}-\mathrm{OCO}(\mathrm{f})$ & -3.0637 \\
$\mathrm{H}-\mathrm{CO}_{2}(\mathrm{t})$ & -3.5435 & & $\mathrm{H}-\mathrm{CO}_{2}(\mathrm{t})$ & -3.2138
\end{tabular}

${ }^{a}$ where $\mathrm{H}-\mathrm{CO}_{2}$ (f) refers to $\mathrm{H}$ bound to $\mathrm{C}$ atom of formate species, $\mathrm{H}-\mathrm{OCO}(\mathrm{f})$ refers to $\mathrm{H}$ bound to one $\mathrm{O}$ atom of formate species, $\mathrm{H}-\mathrm{CO}_{2}(\mathrm{t})$ refers to $\mathrm{H}$ bound to $\mathrm{C}$ atom of on-top species (Figure $4 \mathrm{a}), \mathrm{H}-\mathrm{O}(2) \mathrm{CO}(\mathrm{t})$ refers to $\mathrm{H}$ bound to the $\mathrm{O}(2)$ atom of on-top species (Figure $4 \mathrm{~b}), \mathrm{H}-\mathrm{O}(1) \mathrm{CO}(\mathrm{t})$ refers to $\mathrm{H}$ bound to one $\mathrm{O}(1)$ atom of on-top species (Figure 4c)

system is stabilized in 1.5 and $1.7 \mathrm{eV}$ respectively, for the uncharged surface, as concluded from data shown in Table 6. Moreover, for the latter, a formate adsorbate is formed by bending the $\mathrm{Pt}(1)-\mathrm{O}(1)-\mathrm{C}$ angle (Figure $4 \mathrm{~d})$. At the reference potential, this process requires an activation energy that is $\mathrm{AE}=0.04 \mathrm{eV}$ for $\mathrm{Pt}(100)$ and $\mathrm{AE}=0.08$ $\mathrm{eV}$ for $\mathrm{Pt}(111)$. These values of $\mathrm{AE}$ become zero when the simulated electric potential is lower than $-0.4 \mathrm{eV}$ for both Pt surfaces.
Coordination of the $\mathrm{H}$ atom to the $\mathrm{O}$ atoms of the adsorbed $\mathrm{CO}_{2}$ molecule leads to less stable structures than those defined by direct $\mathrm{H}-\mathrm{Pt}$ interaction (Figure $4 \mathrm{~b}, \mathrm{~d}$ ). Furthermore, the bending of either the $\mathrm{Pt}(1)-\mathrm{O}(1)-\mathrm{C}$ or $\mathrm{O}(1)-\mathrm{C}-\mathrm{O}(2)$ angles in the $\mathrm{H}-\mathrm{O}(2) \mathrm{CO}$ adsorbate would result in a hydrogenated side-on $\mathrm{CO}_{2}$ adsorbate (Figure $4 \mathrm{e})$. The values of $\mathrm{AE}$ for this change in the adsorbate configuration are $\mathrm{AE}=0.20 \mathrm{eV}$ for $\mathrm{Pt}(100)$ and $\mathrm{AE}=0.22$ $\mathrm{eV}$ for $\mathrm{Pt}(111)$. These values of $\mathrm{AE}$ decrease to zero $(-0.2$ $\mathrm{V}$ downward) when the simulated electric potential is shifted negatively. Similarly, the bending of the $\operatorname{Pt}(1)-$ $\mathrm{O}(1)-\mathrm{C}$ and $\mathrm{O}(1)-\mathrm{C}-\mathrm{O}(2)$ angle of the $\mathrm{H}-\mathrm{O}(1) \mathrm{CO}$ adsorbate would generate a new hydrogenated side-on $\mathrm{CO}_{2}$ adsorbate (Figure 4f). The values of $\mathrm{AE}$ for this process are $\mathrm{AE}=$ $0.14 \mathrm{eV}$ for $\mathrm{Pt}(100)$ and $\mathrm{AE}=0.17 \mathrm{eV}$ for $\mathrm{Pt}(111)$. These values of $\mathrm{AE}$ decrease to zero $(-0.3 \mathrm{~V}$ downward) as the simulated electric potential is negatively shifted.

Values of BE and their dependence on the simulated electric potential for the different adsorbates can be seen in Table 7. The stability of these adsorbates decreases from -1.0 to $0 \mathrm{~V}$ and then increases again from 0 to 1.0 $\mathrm{V}$, although the greatest stability is observed at $-1.0 \mathrm{~V}$. The explanation for the potential dependence of $\mathrm{BE}$ values was already discussed in section 3.1.2.

Summarizing, when $\mathrm{H}$ atoms are considered in the definition of the electrochemical interface, the coordination of a $\mathrm{H}$ atom with the $\mathrm{CO}_{2}$ adsorbate leads to the formation of formate adsorbates, on both $\mathrm{Pt}(100)$ and $\mathrm{Pt}(111)$ cluster surfaces over the potential range covering from the reference potential downward. Hydrogen coordination may imply the direct attachment to the $\mathrm{C}$ atom of an adsorbed formate species or the bending of a linearly bonded $\mathrm{C}$-hydrogenated $\mathrm{CO}_{2}$ one. This fact suggests that formate species are the most likely adsorbed intermediates formed in the electrochemical reaction of $\mathrm{CO}_{2}$ on $\mathrm{Pt}$.

\section{Conclusions}

According to our calculations, $\mathrm{CO}_{2}$ adsorption on $\mathrm{Pt}(100)$ and $\mathrm{Pt}(111)$ surfaces implies the simultaneous coordination of two atoms of the molecule, to give side-on and formate configurations. This result might be valid in the experimental potential range including the pzc (potential of zero charge) and the $\mathrm{H}$-adatom potential region. Among these configurations, and regardless the simulated potential, side-on $\mathrm{CO}_{2}$ adsorbates become the most stable ones on both Pt surfaces. In agreement with experiment, larger $\mathrm{BE}$ are always calculated for the $\operatorname{Pt}(100)$ cluster surface.

When $\mathrm{H}$-atoms are also considered in the definition of the electrochemical interface, formate adsorbates become the most stable ones. Because it appears that the formation of $\mathrm{CO}_{2}$-containing adsorbates requires the simultaneous interacion of $\mathrm{CO}_{2}$ and $\mathrm{H}$ adatoms, our

Table 7. Values of $\mathrm{BE}$ for Adsorbates Resulting from $\mathrm{CO}_{2}$ and $\mathrm{H}$ on $\mathrm{Pt}(111)$ and $\mathrm{Pt}(100)$ Surfaces at Different Simulated Electric Potentials (V)

\begin{tabular}{|c|c|c|c|c|c|c|}
\hline \multirow[b]{2}{*}{ pot. } & \multicolumn{3}{|c|}{$\operatorname{Pt}(100)$} & \multicolumn{3}{|c|}{$\operatorname{Pt}(111)$} \\
\hline & $\mathrm{H}$ on-top $\mathrm{CO}_{2}$ formate & $\mathrm{H}$ on-top $\mathrm{CO}_{2}$ on-top & $\mathrm{H}-\mathrm{CO}_{2}(\mathrm{f})$ & $\mathrm{H}$ on-top $\mathrm{CO}_{2}$ formate & $\mathrm{H}$ on-top $\mathrm{CO}_{2}$ on-top & $\mathrm{H}-\mathrm{CO}_{2}(\mathrm{f})$ \\
\hline 1.0 & -4.8563 & -5.4432 & -6.7576 & -4.6679 & -4.7543 & -6.4332 \\
\hline 0.8 & -4.6751 & -4.8466 & -6.2323 & -4.4540 & -4.4430 & -6.0443 \\
\hline 0.6 & -4.3242 & -4.4320 & -5.9768 & -4.2544 & -3.9311 & -5.7548 \\
\hline 0.4 & -4.0875 & -3.9654 & -5.1288 & -3.9912 & -3.2352 & -4.9867 \\
\hline 0.2 & -3.7456 & -3.6543 & -4.9769 & -3.6743 & -2.7658 & -4.7564 \\
\hline 0 & -3.5589 & -3.0120 & -4.5782 & -3.4254 & -2.4560 & -4.1233 \\
\hline-0.2 & -3.9654 & -3.5431 & -5.0123 & -3.7876 & -2.7435 & -4.7475 \\
\hline-0.4 & -4.3547 & -4.1333 & -5.8675 & -4.0923 & -3.2431 & -5.2912 \\
\hline-0.6 & -4.8244 & -4.7654 & -6.5457 & -4.6765 & -3.9652 & -5.7348 \\
\hline-0.8 & -5.3765 & -5.4350 & -7.0913 & -5.0230 & -4.4432 & -6.3754 \\
\hline-1.0 & -5.7452 & -5.7545 & -8.4243 & -5.4439 & -5.0618 & -7.1309 \\
\hline
\end{tabular}


calculations suggest that hydrogenated formate species are the most likely adsorbates formed in the electroformation of reduced $\mathrm{CO}_{2}$ on Pt.

Acknowledgment. This work was financially supported by the Consejo Nacional de Investigaciones Científicas y Técnicas (CONICET), and Comisión de Investi- gaciones Científicas de la Provincia de Buenos Aires (CIC), Argentina. C.F.Z. is a member of the Research Career at Programa de Desarrollo de Ciencias Básicas (PEDECIBA), Uruguay. G.L.E. gratefully acknowledges the University of Quilmes for a research grant.

LA980447+ 